\title{
Cloning, Purification, and Partial Characterization of the Halobacterium sp. NRC-1 Minichromosome Maintenance (MCM) Helicase
}

\author{
Nozomi Sakakibara*,1, Mimi Han ${ }^{1}$, Claire R. Rollor ${ }^{1}$, Rebecca C. Gilson ${ }^{1}$, Courtney Busch ${ }^{2}$, \\ Gunyoung Heo ${ }^{1}$ and Zvi Kelman ${ }^{1}$ \\ ${ }^{I}$ University of Maryland Biotechnology Institute, Center for Advanced Research in Biotechnology, 9600 Gudelsky Drive, \\ Rockville, MD 20850, USA \\ ${ }^{2}$ Department of Cell Biology and Molecular Genetics, University of Maryland College Park, College Park MD 20742, \\ USA
}

\begin{abstract}
The MCM gene from the archaeon Halobacterium, with and without its intein, was cloned into an Escherichia coli expression vector, overexpressed and the protein was purified and antibodies were generated. The antibodies were used to demonstrate that in vivo only the processed enzyme, without the intein, could be detected.
\end{abstract}

\section{INTRODUCTION}

Chromosomal DNA replication is an essential process for all organisms. It insures the accurate duplication of the genetic information prior to cell division. The process is highly controlled and coordinated, as aberrant DNA replication can lead to malignancies and cancer. The process is conserved in all organisms including bacteria, archaea, eukarya, viruses, and bacteriophages.

Halobacterium sp. NRC-1 is a halophilic archaeon with an optimal growth temperature of $42^{\circ} \mathrm{C}$ and a $2 \mathrm{hr}$ generation time [1]. The genome of Halobacterium sp. NRC-1 consists of $2.5 \mathrm{Mb}$ and encodes for about 2,600 proteins. The entire genome consists of one large chromosome $(2 \mathrm{Mb})$ and two extrachromosomal replicons, pNRC100 $(191 \mathrm{~kb})$ and pNRC200 (365 kb).

The minichromosome maintenance (MCM) complex is thought to function as the replicative helicase of archaea and eukarya [2,3]. One MCM homologue has been identified in the genome of Halobacterium. In contrast to other archaeal MCM proteins studied to date, the Halobacterium protein contains an intein.

In this study we describe the isolation, purification and in vivo identification of the single $\mathrm{MCM}$ helicase from $\mathrm{Ha}$ lobacterium sp. NRC-1. It was found that in vivo only the mature enzyme, from which the intein has been removed, could be identified.

\section{MATERIALS AND METHODS}

\section{Sequence Alignment of MCM Proteins}

The Halobacterium sp. NRC-1 MCM protein sequence was aligned with four other archaeal MCM proteins (Methanothermobacter thermautotrophicus, Thermoplasma acidophilum, Sulfolobus solfataricus and Archaeoglobus fulgidus) using the MUSCLE algorithm (http://www.ebi.ac. uk/muscle/).

*Address correspondence to this author at the University of Maryland Biotechnology Institute, Center for Advanced Research in Biotechnology, 9600 Gudelsky Drive, Rockville, MD 20850, USA;

E-mail: sakakiba@umbi.umd.ed

\section{Cloning the MCM Gene}

The Halobacterium $s p$. NRC-1 MCM gene was amplified using PCR from genomic DNA (kindly provided by Brian Berquist). The PCR reaction was performed with $100 \mathrm{ng}$ genomic DNA, $200 \mu \mathrm{M}$ dNTPs, 5 units of Optimase ${ }^{\mathrm{TM}}$ polymerase (Transgenomic), 1 x Optimase reaction buffer, 1.5 $\mathrm{mM} \mathrm{MgSO}_{4}, 10 \%$ DMSO and $0.4 \mu \mathrm{M}$ of primers, N101 (5'CCGCTCGAGGCTAGCCATATGGATCCGGACCTGGCCGACGATTACATCAGCC-3') and N102 (5'-CCGCTCGAGCCATGGCTAGATCGAGCGCAAGTGGTCCGTGTTC-3'), where the XhoI restriction site is underlined, and the NdeI site shown in bold type. Twenty PCR cycles were performed as follows: denaturation at $95^{\circ} \mathrm{C}$ for $2 \mathrm{~min}$, annealing at $70^{\circ} \mathrm{C}$ for 45 seconds, and elongation at $72^{\circ} \mathrm{C}$ for 5 minutes. The PCR product was purified using the QIAquick PCR purification kit (Qiagen), digested with XhoI and ligated into the XhoI site of pBluescript KS(Stratagene). The sequence was confirmed by sequencing and the clone was designated pBS-MCM. The gene encoding MCM was excised from the $\mathrm{pBS}-\mathrm{MCM}$ vector by cleavage at the NdeI and XhoI sties and cloned into pET-16b vector (Novagene). This clone is designated pET-MCM.

To generate the MCM gene construct without the intein, a PCR-based method was used [4] using pBS-MCM as template. The PCR reactions were performed as described above with the following two primer sets to amplify the two exteins. One set was N101 together with 5'- GGGGCGCGATGTTCTGCACGTAGGAGATCATCTGGGACTTCCCGGTTCCCGGGTCACC-3' and the other set was N102 together with 5'-GGTGACCCGGGAACCGGGAAGTCCCAGATGATCTCCTACGTGCAGAACATCGCGCCCC-3'. Two exteins encoding PCR products were purified using the QIAquick purification kit and used as template (10 ng each) for PCR amplification using N101 and N102 as primers. The resulting PCR product contained the MCM gene minus the intein. This product was cloned into pET-16b, sequenced, and designated pET-MCMint.

\section{Purification of the MCM Proteins}

Plasmids containing the genes encoding for the fulllength MCM and the protein without intein were transformed 
into Codon plus Escherichia coli cells (Stratagene). Cells were grown in $\mathrm{LB}$ media at $37^{\circ} \mathrm{C}$. When the $\mathrm{OD}_{600}$ reached 0.6 , protein expression was induced by the addition of IPTG (1 $\mathrm{mM}$ final concentration) and the cells were grown for an additional 4 hours. Cells were harvested and stored at $-80^{\circ} \mathrm{C}$. Protein purification was carried out at $4^{\circ} \mathrm{C}$ as follows. Cells were thawed on ice in lysis buffer containing $10 \mathrm{mM}$ imidazole, $3 \mathrm{M} \mathrm{NaCl}, 0.5 \mathrm{M} \mathrm{KCl}, 20 \mathrm{mM}$ Tris- $\mathrm{HCl}(\mathrm{pH}$ 7.6) and $20 \%$ glycerol and disrupted by sonication. The lysate was centrifuged for $15 \mathrm{~min}$ at $15,000 \mathrm{rpm}$ in JA-17 rotor (Beckman). The pellet was kept and the supernatant was incubated with Ni-column resin for $1 \mathrm{hr}$ with gentle shaking. Following incubation, the resin was poured into a column and washed with lysis buffer containing $10 \mathrm{mM}$ imidazol. The MCM protein was step eluted with 50,100, 200 and $300 \mathrm{mM}$ of imidazol.

Since only a small fraction of the induced MCM protein was found in the soluble fraction, the protein was also purified from the pellet using denaturing conditions in urea. The cell pellet was resuspended in buffer containing $8 \mathrm{M}$ urea and $20 \mathrm{mM}$ Tris- $\mathrm{HCl}(\mathrm{pH}$ 7.6) followed by centrifugation for 15 min at 15,000 rpm in a JA-17 rotor. The supernatant was incubated with Ni-column resin for $1 \mathrm{hr}$ with gentle shaking.
Following incubation, the resin was poured into a column and washed with lysis buffer containing $10 \mathrm{mM}$ imidazol. The MCM protein was eluted using step elution in lysis buffer containing $6 \mathrm{M}$ urea and 50,100 , and $300 \mathrm{mM}$ imidazole. The fraction with the highest MCM concentration (300 $\mathrm{mM}$ imidazol) was dialyzed in buffer containing $20 \mathrm{mM}$ Tris- $\mathrm{HCl}$ (pH 7.6), $3 \mathrm{M} \mathrm{NaCl}, 0.5 \mathrm{M} \mathrm{KCl}$, and $20 \%$ glycerol. The proteins were flash frozen in liquid nitrogen and kept at $-80^{\circ} \mathrm{C}$.

\section{Mass Spectrometry Analysis of the E. coli Expressed Pro- teins}

To confirm that the purified proteins are indeed the recombinant Halobacterium MCM proteins a matrix-assisted laser desorption ionization time-of-flight (MALDI-TOF) mass spectrometric (MS) analysis was used. MALDI-TOF MS was performed using an AB4700 Proteomics Analyzer (Applied Biosystems, Framingham, MA) using in-gel tryptic digestion of Coomassie-stained protein bands. Dry peptide samples were dissolved in $5 \mathrm{mg} / \mathrm{ml} \alpha$-cyano-4-hydroxycinnamic acid in $50 \%$ acetonitrile containing $0.1 \%$ trifluoroacetic acid, and manually spotted onto an ABI 01 192-6-AB target plate. MS-mode acquisitions consisted of 1,000 laser shots averaged over 20 sample positions. For

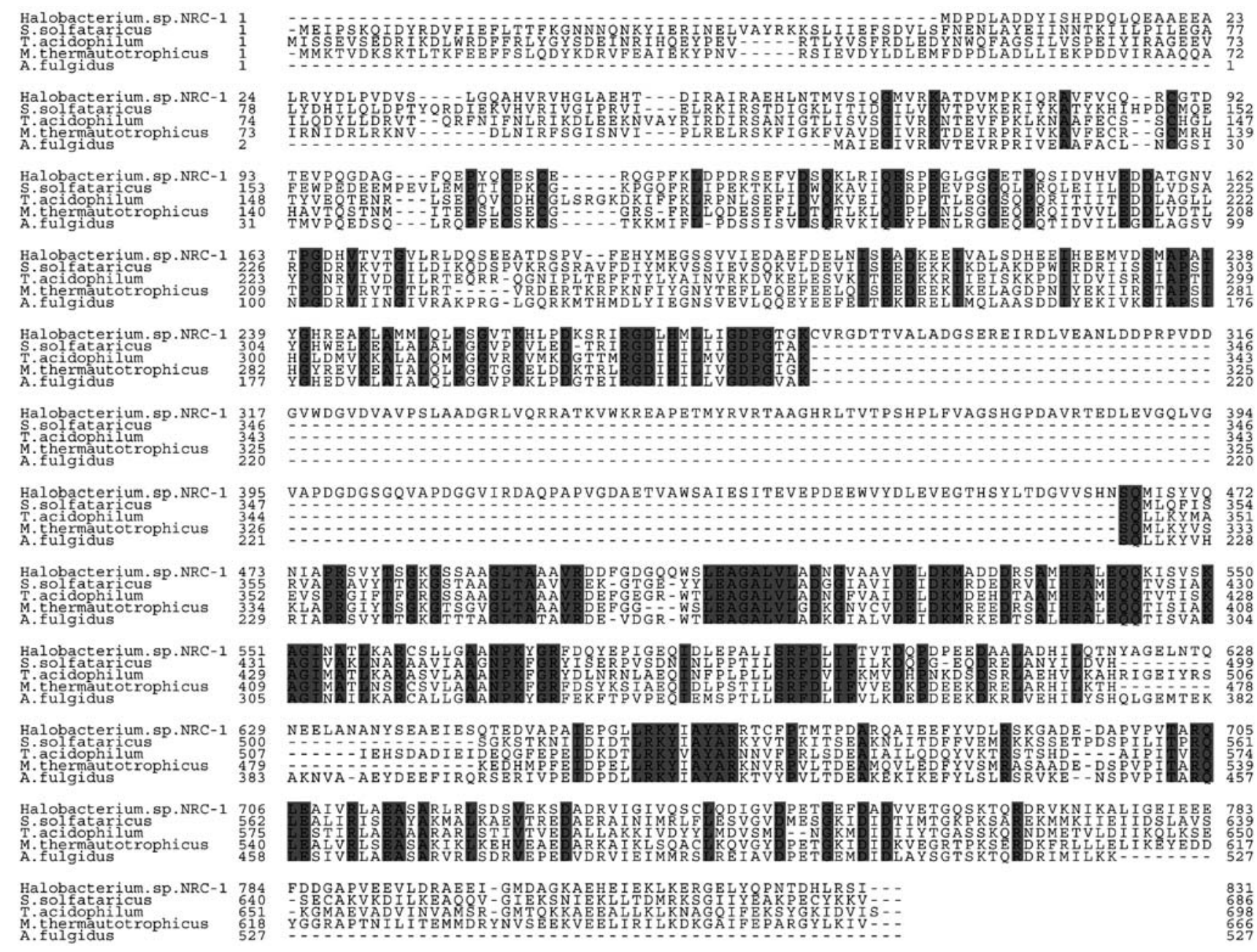

Fig. (1). Alignment of full length Halobacterium MCM protein. Amino acid sequence alignment of five archaeal MCM helicases: Halobacterium sp. NRC-1, S. solfataricus, T. acidophilum, M. thermautotrophicus, and A. fulgidus. Highlighted residues are conserved in all five proteins. The long inserted sequence found in Halobacterium sp. NRC-1 is the intein. 
Table 1. Amino Acid Analysis of MCM Proteins

\begin{tabular}{|c|c|c|c|c|c|c|}
\hline Organism & Length & KDa & $\begin{array}{c}\text { Negativly } \\
\text { charged: } E+D(\%)\end{array}$ & $\begin{array}{c}\text { Positively } \\
\text { scharged: } \mathbf{K}+\mathrm{R}(\%)\end{array}$ & Ratio: $(\mathbf{E}+\mathbf{D}) /(\mathbf{K}+\mathbf{R})$ & pI \\
\hline Halobacterium sp. NRC-1 with intein & 831 & 90.5 & $165(19.9)$ & $74(8.9)$ & 2.2 & 4.4 \\
\hline M. thermautotrophicus & 666 & 75.6 & $121(18.2)$ & $100(15.0)$ & 1.2 & 5.2 \\
\hline T. acidophilum & 698 & 78.9 & $109(15.6)$ & $94(13.5)$ & 1.2 & 5.5 \\
\hline A. fulgidus & 698 & 78.8 & $116(16.6)$ & $102(14.6)$ & 1.1 & 5.7 \\
\hline
\end{tabular}

MS/MS-mode acquisitions, 3,000 laser shots were averaged over 30 sample positions for PSD fragments. Automated combined acquisition of MS and MS/MS data was controlled with 4000 Series Explorer software 3.0. Data analysis was performed with GPS Explorer software 3.5 utilizing Mascot 2.0 (MatrixScience, London, UK) as the search engine. During searching, the mass tolerance was $0.08 \mathrm{Da}$ for the precursor ions and $0.2 \mathrm{Da}$ for the fragment ions. A protein was listed as identified protein when the MOWSE score was higher than the MOWSE score at which statistical significance $(\mathrm{p}<0.05)$ occurred for that particular search.

\section{Generation of Antibodies}

Urea purified MCM protein without intein was used to generate rabbit polyclonal antibodies by Cocalico Biologicals, Inc.

\section{Preparation of Halobacterium Cell Extract}

Halobacterium sp. NRC-1 (ATCC number 700922) was grown in GN101 media $\left(250 \mathrm{~g} / \mathrm{L} \mathrm{NaCl}, 20 \mathrm{~g} / \mathrm{L} \mathrm{MgSO}_{4}, 2 \mathrm{~g} / \mathrm{L}\right.$ $\mathrm{KCl}, 3 \mathrm{~g} / \mathrm{L}$ sodium citrate, $10 \mathrm{~g} / \mathrm{L}$ Oxoid brand bacteriological peptone) with the addition of $1 \mathrm{~mL} / \mathrm{L}$ trace elements solution (31.5mg/L $\quad \mathrm{FeSO}_{4} \cdot 7 \mathrm{H}_{2} \mathrm{O}, 4.4 \mathrm{mg} / \mathrm{L} \quad \mathrm{ZnSO}_{4} \cdot 7 \mathrm{H}_{2} \mathrm{O}, 3.3 \mathrm{mg} / \mathrm{L}$ $\left.\mathrm{MnSO}_{4} \cdot \mathrm{H}_{2} \mathrm{O}, 0.1 \mathrm{mg} / \mathrm{L} \mathrm{CuSO} \cdot 5 \mathrm{H}_{2} \mathrm{O}\right)$ at $42^{\circ} \mathrm{C}$ with shaking at $220 \mathrm{rpm}$. Beveled flasks were used to ensure proper oxygenation. Cultures were centrifuged at $8000 \mathrm{x}$ g and a cell pellet from $25 \mathrm{ml}$ of culture was resuspended in $1 \mathrm{ml}$ of buffer containing $50 \mathrm{mM}$ potassium phosphate ( $\mathrm{pH} 7.0), 1 \mathrm{M} \mathrm{NaCl}$, and $10 \% \quad \beta$-mercaptoethanol. The resuspended cells were sonicated on ice followed by centrifugation at $13,000 \mathrm{rpm}$ for $10 \mathrm{~min}$ at $4^{\circ} \mathrm{C}$. The supernatant was kept at $-20^{\circ} \mathrm{C}$.

\section{Western Analysis}

MCM protein with intein (20 ng) and without intein ( $1 \mathrm{ng})$ and Halobacterium cell extract $(0.5 \mu \mathrm{g}$ and $1 \mu \mathrm{g})$ were separated on $10 \%$ SDS-PAGE. The gel was then electroblotted onto nitrocellulose BA83 membranes (Whatman) followed by Western analysis using 1:500 dilution of rabbit anti-MCM polyclonal antibodies and goat anti-rabbit antibody coupled to horseradish peroxidase (Epitomics) as secondary antibody. The blot was developed using ECL (GE healthcare) followed by exposure to X-ray film.

\section{RESULTS AND DISCUSSION}

\section{Sequence Analysis of Halobacterium MCM Protein}

Multiple alignment sequence analysis of archaeal MCM proteins revealed that the Halobacterium protein contains a large insertion (Fig. 1). Analysis of the insertion sequence and its integration site $[5,6]$ clearly suggest that it is an intein. The intein is inserted in the middle of the Walker-A motif [7], a highly conserved motif which is found in all members of the $\mathrm{AAA}^{+}$family of ATPases [8,9]. The sequence of the motif in Halobacterium MCM is GDPGTGKS and the intein is located between the highly conserved Lys and Ser residues.

The alignment also revealed that the C-terminal part of the MCM protein is more conserved than the $\mathrm{N}$-terminal portion. The $\mathrm{C}$-terminal part of the molecule contains the $\mathrm{AAA}^{+}$catalytic domains, known to be highly conserved among different members of this family of enzymes. Nevertheless, the Halobacterium MCM as a whole clearly shows amino acid sequence similarity to other member of this family of helicases.

The sequence of the Halobacterium MCM also revealed that it contains a relatively small number of basic residues in comparison to other MCM proteins, and the ratio between negative and positive residues is much higher than in MCM proteins from non-halophilic archaea (Table 1). Similar observations of charge distribution on proteins have also been

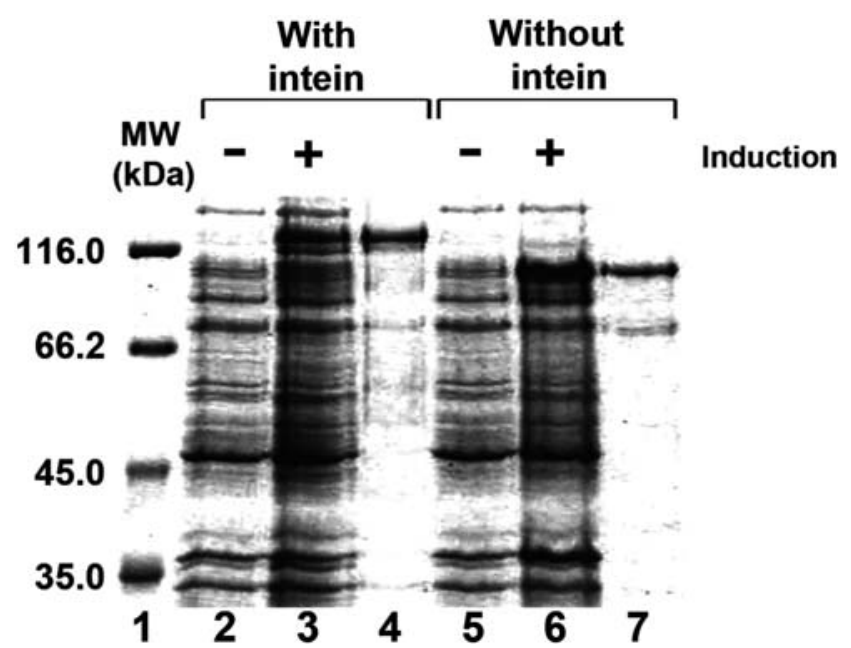

Fig. (2). Purification of the Halobacterium MCM helicase. Uninduced and induced E. coli cells harboring pET-MCM (lanes 2 and 3 ) and pET-MCMint (lanes 5 and 6) and the purified MCM protein $(0.5 \mu \mathrm{g})$ with intein (lane 4) and without intein (lane 7) were fractionated on $10 \%$ SDS-PAGE. Lane 1, molecular weight markers. 
observed when the entire proteome of Halobacterium was analyzed [10].

\section{Purification and Identification of Halobacterium MCM Helicase}

The MCM protein containing the intein was cloned into an $E$. coli expression vector and purified as described in "Material and Methods". Although most of the proteins were not soluble, a small fraction was soluble and this fraction was purified (Fig. 2 lane 4). However, the intein is still pre- sent in the protein. It is known that in other intein-containing proteins expressed in $E$. coli, the intein is excised during induction prior to purification. The observation that the intein does not excise itself but stays as a part of the purified MCM suggests that either the in vivo conditions in E. coli (e.g. salt) are not favorable for the intein protease activity or that the protein is not properly folded.

In order to get a MCM protein without the intein, the intein was recombinantly removed from the gene and the
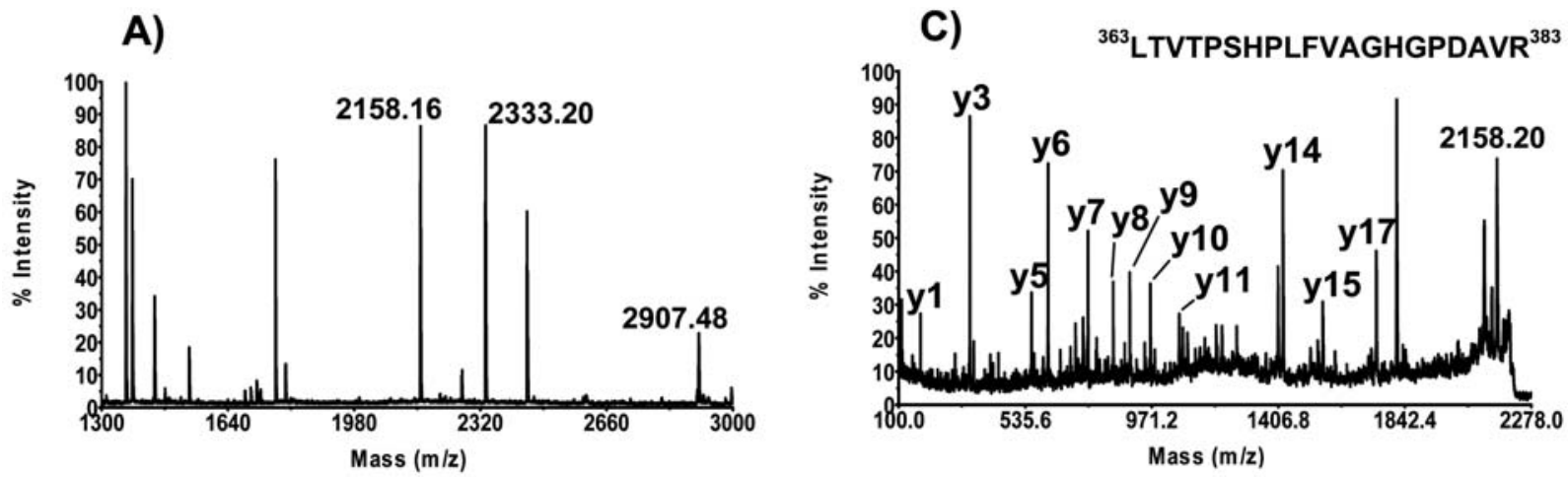

B)

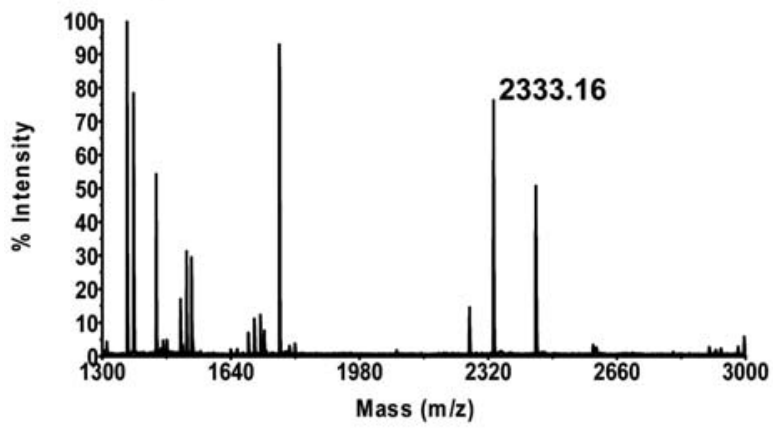

D)

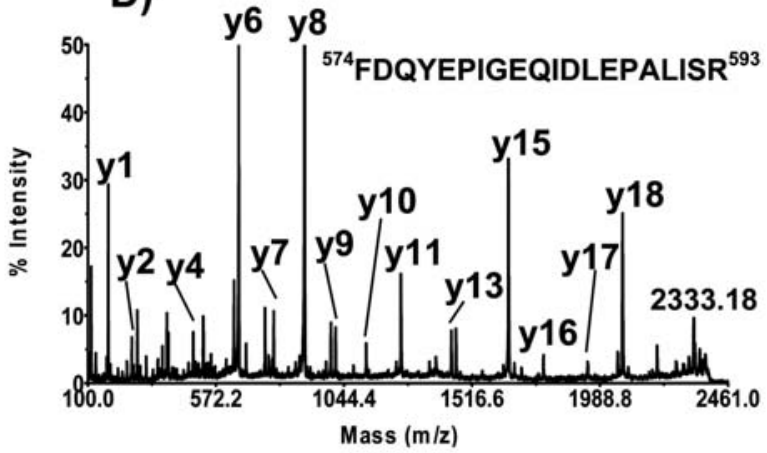

E)

MDPDLADDYISHPDQLQEAAEEALRVYDLPVDVSLGQAHVRVHGLAEHTDIRAIRAEHLNTMVSIQGMVR 70

KATDVMPKIQRAVFVCQRCGTDTEVPQGDAGFQEPYQCESCERQGPFKLDPDRSEFVDSQKLRIQESPEG 140

LGGGETPQSIDVHVEDDATGNVTPGDHVTVTGVLRLDQSEEATDSPVFEHYMEGSSVVIEDAEFDELNIS 210

EADKEEIVALSDHEEIHEEMVDSMAPAIYGHREAKLAMMLQLFSGVTKHLPDKSRIRGDLHMLLIGDPGT 280

GKCVRGDTTVALADGSEREIRDLVEANLDDPRPVDDGVWDGVDVAVPSLAADGRLVQRRATKVWKREAPE 350

TMYRVRTAAGHRLTVTPSHPLFVAGSHGPDAVRTEDLEVGQLVGVAPDGDGSGQVAPDGGVIRDAQPAPV 420

GDAETVAWSAIESITEVEPDEEWVYDLEVEGTHSYLTDGVVSHNSQMISYVQNIAPRSVYTSGKGSSAAG 490

LTAAAVRDDFGDGQQWSLEAGALVLADNGVAAVDELDKMADDDRSAMHEALEQQKISVSKAGINATLKAR 560

CSLLGAANPKYGRFDQYEPIGEOIDLEPALISRFDLIFTVTDQPDPEEDAALADHILQTNYAGELNTQNE 630

ELANANYSEAEIESQTEDVAPAIEPGLLRKYIAYARRTCFPTMTPDARQAIEEFYVDLRSKGADEDAPVP 700

VTARQLEAIVRLAEASARLRLSDSVEKSDADRVIGIVQSCLQDIGVDPETGEFDADVVETGQSKTQRDRV 770

KNIKALIGEIEEEFDDGAPVEEVLDRAEEIGMDAGKAEHEIEKLKERGELYQPNTDHLRSI

831

Fig. (3). Mass spectroscopy analysis of the E. coli expressed proteins. MALDI-TOF spectra of Halobacterium MCM with (A) and without (C) intein were performed as described in "Material and Methods". The 2158.16 and 2333.16 peaks were analyzed using MS/MS (C and D, respectively) as described in "Material and Methods". Panel E shows the position of the peptide in the MCM amino acid sequence. Shaded areas show the location of the intein. The peptide corresponding to the 2158.16 peak is underlined and that for the 2333.16 peak is double underlined. 


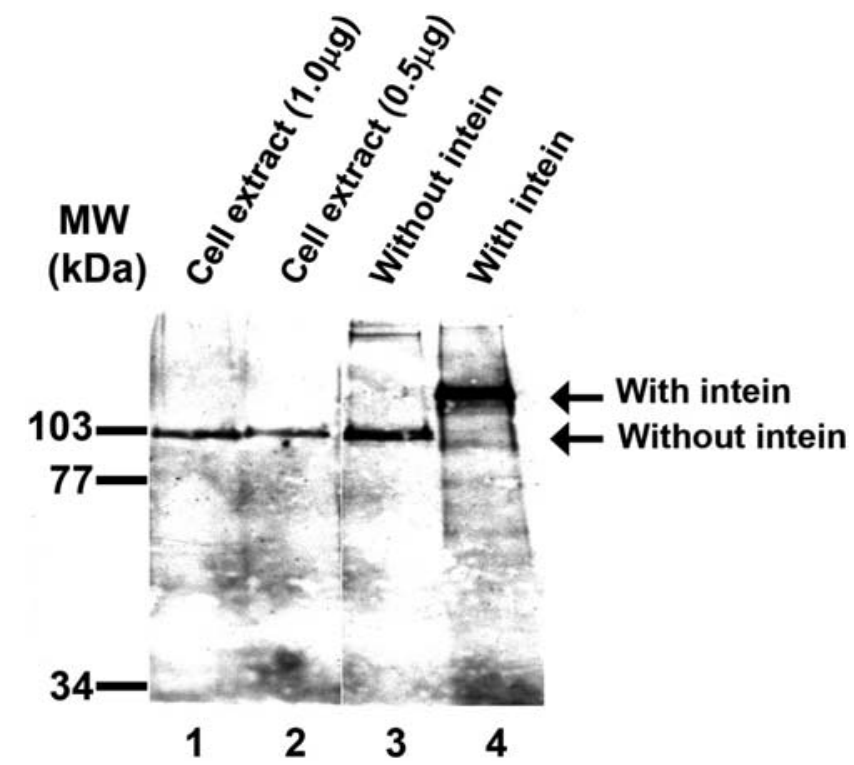

Fig. (4). Only MCM protein without intein can be detected in $\mathrm{Ha}$ lobacterium cells. Western analysis of Halobacterium cell extract and recombinant MCM protein was performed as described in "Material and Methods". Lane 1, cell extract (1 $\mu \mathrm{g})$; lane 2, cell extract $(0.5 \mu \mathrm{g})$; lane 3 , purified MCM protein without intein (1 ng); lane 4, purified full length MCM (20 ng). To the left are the positions of the molecular weight markers.

expressed protein was purified as described in "Material and Methods" (Fig. 2 lane 7).

When analyzed on SDS-PAGE, both proteins migrate more slowly than predicted from their calculated molecular mass. The protein with intein migrates as a $123 \mathrm{kDa}$ instead of $90 \mathrm{kDa}$ molecule and the recombinant protein without intein migrates as $98 \mathrm{kDa}$ instead of $71 \mathrm{kDa}$ molecule. To confirm that the purified proteins are indeed the MCM proteins MALDI-TOF MS analysis was performed. The protein containing intein (Fig. 3A) and without intein (Fig. 3B) were analyzed. Both proteins contain peptides corresponding to the Halobacterium MCM proteins.

The peaks at $\mathrm{m} / \mathrm{z}$ positions 2158.16 and 2907.48 are present only in the MCM protein containing the intein; (Fig. 3A) they are absent in Fig. (3B). This suggests that these peaks originate from the MCM intein. A MS/MS analysis of the 2158.16 peak revealed that it is, indeed, the peptide from the intein sequence (Fig. 3C and E). Another peak, 2333.20, is found in both proteins (Fig. 3A and $\mathbf{B}$ ). A MS/MS analysis of the peak showed that it is derived from a peptide located in the MCM protein but outside the intein (Fig. 3D and E). The combined results of the MS and MS/MS analysis recovered $43 \%$ and $50 \%$ of MCM protein with and without intein, respectively (data not shown). This suggests, with high con- fidence, that the two recombinant proteins isolated are the Halobacterium MCM protein.

\section{Detection of Halobacterium MCM Protein in vivo}

As described above (Fig. 1), the Halobacterium MCM gene encodes for a protein that contains an intein. As the intein is located in a highly conserved and important domain for helicase activity, it is presumed that, in vivo, the intein excises itself from the protein after translation and ligates the two other peptide fragments (exteins). Thus, the mature MCM protein will not contain the intein and will therefore be active [11]. It was therefore expected that in Halobacterium cells only the mature protein would be present. To determine if this is the case a western analysis was performed using cell extract and anti-MCM antibodies. As shown in Fig. (4) lanes 1 and 2, only the mature MCM, without the intein, could be detected.

\section{ACKNOWLEDGEMENTS}

We would like to thank Dr. Illarion V. Turko for the mass spectrometry analysis, Dr. Brian Berquist for providing Halobacterium genomic DNA and Dr. Lori Kelman for a critical reading of the manuscript. This work was supported by Grants from the National Science Foundation (MCB0237483 and MCB-0450695) to ZK.

\section{REFERENCES}

[1] Grant WD. Halobacterium, vol 1 edn 2nd. Edited by Garrity GM, 2001.

[2] Kelman LM, Kelman Z. Archaea: an archetype for replication initiation studies? Mol Microbiol 2003; 48: 605-615.

[3] Kelman Z, White MF. Archaeal DNA replication and repair. Curr Opin Microbiol 2005; 8: 669-676.

[4] Kasiviswanathan R, Shin JH, Melamud E, Kelman Z. Biochemical Characterization of the Methanothermobacter thermautotrophicus Minichromosome Maintenance (MCM) Helicase N-terminal Domains. J Biol Chem 2004; 279: 28358-28366.

[5] Pietrokovski S. Conserved sequence features of inteins (protein introns) and their use in identifying new inteins and related proteins. Protein Sci 1994; 3: 2340-2350.

[6] Pietrokovski S. Modular organization of inteins and C-terminal autocatalytic domains. Protein Sci 1998; 7: 64-71.

[7] Walker JE, Saraste M, Runswick MJ, Gay NJ. Distantly related sequences in the alpha- and beta-subunits of ATP synthase, myosin, kinases and other ATP-requiring enzymes and a common nucleotide binding fold. EMBO J 1982; 1: 945-951.

[8] Neuwald AF, Aravind L, Spouge JL, Koonin EV. AAA ${ }^{+}$A class of chaperone-like ATPases associated with the assembly, operation, and disassembly of protein complexes. Genome Res 1999; 9: 2743.

[9] Ogura T, Wilkinson AJ. AAA+ superfamily ATPases: common structure--diverse function. Genes Cells 2001; 6: 575-597.

[10] Kennedy SP, Ng WV, Salzberg SL, Hood L, DasSarma S. Understanding the adaptation of Halobacterium species NRC-1 to its extreme environment through computational analysis of its genome sequence. Genome Res 2001; 11: 1641-1650.

[11] Saleh L, Perler FB. Protein splicing in cis and in trans. Chem Rec 2006; 6: 183-193. 